\title{
THE BLACK BOX OF SCHOOLING. A CULTURAL HISTORY OF THE CLASSROOM,
}

por SjaAk Braster, Ian Grosvenor y María del Mar del Pozo (eds.). Bruselas: P. I. E - Peter Lang, 2011, 330 páginas. ISBN: 978-90-5201-760-0.

La Black Box of Schooling —o Caja Negra de la escolarización- da significado a todos aquellos procesos que suceden dentro de la escuela, en el interior del aula, utilizado como metáfora para designar la cultura práctica de la escuela. En este sentido, los editores del libro, Sjaak Braster, Ian Grosvenor y María del Mar del Pozo, nos presentan, desde distintas perspectivas metodológicas y fuentes, este extraño y menos explorado espacio a investigar.

Hasta la aparición del término Caja Negra acuñado por Lacey en 1970, y recuperado por Depaepe y Simon veinticinco años más tarde, ${ }^{1}$ existía una tendencia en historia de la educación en centrar las investigaciones en el estudio pedagógico de los legados escritos — teoría de la educación y política educativa- La entrada en escena de los estudios sobre la vida de las aulas revolucionó en cierto modo las investigaciones históricas centrando su interés en el estudio de la historia cultural y social de la escuela en general, y de las entrañas del aula en concreto, hasta entonces prácticamente desconocida. ${ }^{2}$ De este modo, los distintos artefactos que constituían la escuela han resultado ser el centro de investigación para comprender las distintas manifestaciones culturales y sociales que se da-

\footnotetext{
${ }^{1}$ El término Black Box o Caja Negra fue utilizado por primera vez por la psicología conductista a principios de siglo xx. La Caja Negra de Watson servía para señalar los procesos cognitivos mentales no medibles directamente y que se encontraban entre el estímulo y la respuesta. El 1970, Lacey, desde la sociología, utilizó el mismo término para intentar comprender la relación entre fracaso escolar y clase social.

${ }^{2}$ Sjaak Braster, Ian Grosvenor, María del Mar del Pozo, «Opening the Black Box of Schooling. Methods, Meanings and Mysteries», en The Black Box of Schooling. A cultural History of the Classroom, eds. Sjaak Braster, Ian Grosvenor y María del Mar del Pozo (Brussels: P. I. E - Peter Lang, 2011), 12.
} 
ban en su día a día. En este sentido, estos artefactos constituyeron un auténtico descubrimiento arqueológico:

Historians of education have in recent years suggested that school in general and classrooms in particular can be viewed and interpreted as archaeological sites where the objects and traces of past practice can be exposed through careful attention to the strata of detritus that is left sediment over time. Any school or classroom, according to this viewpoint, can be regarded as a site where past encounters and antagonisms can be identified, classified, recorded and revealed through material objects arranged, replaced, removed or built as permanent features. ${ }^{3}$

Está analogía con la arqueología, que presenta Burke, no es en vano. Como el arqueólogo, el investigador en historia de la educación que tiene como objeto de estudio la Caja Negra parte de reconstruir la vida escolar a partir de las manifestaciones materiales. La cultura material y social se convierte, entonces, en fuente de estudio.

\section{ADENTRÁNDONOS EN LA CAJA NEGRA}

El libro se divide en cinco bloques que parten de un eje vertebral común: la fuente. En el primer bloque, se utilizan imágenes y otras representaciones del aula - fotografías, murales, copias de pinturas, cuadros, litografías, etc. - como fuente para abrir y aflorar la Caja Negra. La segunda parte se centra en los escritos y documentos producidos dentro del aula y/o en la escuela. Le sigue el bloque liderado por los egodocumentos -memorias y experiencias personales, autobiografías e historias orales-. El cuarto bloque apunta hacia el espacio y el diseño del aula, a través del estudio arquitectónico, los murales y las transformaciones espaciales. Y en último lugar, un estudio sobre los objetos materiales del

\footnotetext{
${ }^{3}$ Catherine Burke, «"Education through Art". The School Mural as Extended Architecture», en The Black Box of Schooling, 238: «Historiadores de la educación han sugerido en los últimos años que la escuela en general, y el aula en particular, pueden ser vistos e interpretados como lugares arqueológicos donde los objetos y los rastros de las prácticas del pasado pueden quedar expuestos como estratos sedimentados con el paso del tiempo. Cualquier escuela o aula, bajo este punto de vista, puede ser considerada como un sitio donde los encuentros y antagonismos del pasado pueden ser identificados, clasificados, grabados y revelados a través de objetos materiales que pueden ser dispuestos, substituidos, eliminados o incorporados como características permanentes».
} 
aula. Cada capítulo presenta sus particularidades que nos ayudan a desentrañar la Caja Negra, a comprender sus misterios y significados.

Más allá de las conclusiones a las que llegan los autores en su proceso de investigación, a lo largo de la lectura de los distintos capítulos se plantea un diálogo alrededor de la utilidad de los artefactos culturales y sociales como fuente de estudio de la Caja Negra, así como sus potencialidades y sus limitaciones. Aunque ya no se discute su utilidad como fuente, cabe destacar cómo se plantea la trama desde una dualidad simbiótica. Por una parte, las fuentes no textuales pueden y deberían prestar su apoyo a las fuentes escritas. Braster por ejemplo, reconoce que las imágenes escolares pueden ser una fuente válida como sostén de los documentos escritos, pero también una necesidad en la investigación histórica, ya que pueden explicarnos cosas que quedarían ocultas si solo dispusiéramos de fuentes orales y escritas, ${ }^{4}$ del mismo modo que lo apuntaba Buck-Morss en Globalization, Cosmopolitanism, Politics, and the Citizen. ${ }^{5}$

Por otra parte, otros documentos que han entrado en la escena de las investigaciones como los libros de registro escolar, libros de texto, ${ }^{6}$ murales, instantáneas de actos, cartas y diarios de maestras, etc., pueden ser fuente primaria valiosa si se combinan con otras fuentes, como apunta en su capítulo Susannah Wright. ${ }^{7}$ En todo caso, la triangulación de distintas fuentes, textuales o no, parece ser siempre necesaria para no quedar demasiado ligado a la fuente y perder así la percepción holística del fenómeno a estudiar.

\footnotetext{
${ }^{4}$ Sjaak Braster, «Educational Change and Dutch Classroom Photographs. A Qualitative and Quantitative Analysis», en The Black Box of Schooling, 36.

${ }^{5}$ Susan Buck-Morss, «Globalization, Cosmopolitanism, Politics, and the Citizen», Journal of Visual Culture, 1 (3), (2002): 331

${ }^{6}$ Entre algunos de los grupos pioneros que se dedican al estudio de los libros de texto podemos encontrar el Centro de Investigación MANES de la Universidad Nacional Española a Distancia (UNED), liderado por la Dra. Gabriela Ossenbach, con dos líneas de trabajo. La primera de carácter instrumental —elaboración de un censo de libros escolares—y la segunda investigadora. Para más información, véase su página web: http://www2.uned.es/manesvirtual/ProyectoManes/index.htm. Otro grupo, por ejemplo, es el instituto alemán Georg Eckert, dedicado, desde una visión multidisciplinar, al estudio de los libros de textos. Este instituto actúa como coordinador y mediador en proyectos internacionales alrededor de los libros de texto. Para más información: http://www.gei.de/en/home.html.

${ }^{7}$ Susannah Wright, «Inside the Black Box? Log Books from Late $19^{\text {th }}$ and Early $20^{\text {th }}$ Century English Elementary Schools», en The Black Box of Schooling, 137.
} 
Este libro lleva a plantearnos estas discusiones alrededor de las fuentes utilizadas para el estudio de la Caja Negra, y al mismo tiempo a ofrecernos una visión plural de lo que aconteció dentro del aula a través de su cultura social y material; a su vez, también plantea algunos límites al respecto del uso de las mismas.

Todas las fuentes ofrecen sus limitaciones y posibilidades, aunque nos ayuden a comprender un mismo propósito: la Caja Negra. En su capítulo sobre los egodocumentos de maestros, Viñao apunta que cada una de las fuentes, por sus particularidades, tiene sus ventajas e inconvenientes, y que, por lo tanto, es trabajo del investigador determinar si la fuente en cuestión le sirve para su propósito, si la información que se extrae es relevante o no. ${ }^{8}$

Muy a menudo, sus limitaciones son producto de lo que la fuente no nos enseña o de la adecuación de nuestras maneras de mirar, de interrogarnos. A veces esta información que falta, que no se presenta o que se esconde fuera de la mirada del investigador, podría resultar crucial para comprender parte de la complejidad del fenómeno, y para arriesgarnos en una interpretación que diera respuesta a algunas de nuestras preguntas. ¿Pero es crucial para nuestra investigación responder a todas las preguntas que se suscitan a lo largo de ella? O, dicho de otra forma, ¿existe alguna fuente que dé todas las respuestas? No, pero esto tampoco supone invalidar la fuente. Por ejemplo, para Grosvenor las láminas escolares son unas fuentes que carecen de información referente al impacto que causaron en la formación de la subjetividad de los alumnos, ${ }^{9}$ pero al mismo tiempo, nos hablan de las metodologías que se proponían para el aula. Para conocer su impacto, necesitaríamos completar la información con otras fuentes gráficas, como fotografías o filmes educativos.

Del mismo modo, Wright en su trabajo con los diarios de registros de escuela se plantea uno de los obstáculos que el investigador debe tener en cuenta para no caer en interpretaciones que se escapan de la fuente:

\footnotetext{
${ }^{8}$ Antonio Viñao, «Teachers' Egodocuments as a Source of Classroom History. The Case of Autobiographies, Memoirs and Diaries», en The Black Box of Schooling, 143.

${ }^{9}$ Ian Grosvenor, ««To Act on the Minds of Children». Paintings into Schools and English Education», en The Black Box of Schooling, 51.
} 
To make sense of the sometimes euphemistic and indirect entries in log books relevant to my areas of inquiry I have drawn on other primary sources and secondary research. Even with this additional evidence, however, there is a need for caution, because using this strategy one is in danger of putting words into teachers' mouths, reading into their words something they did not intend. ${ }^{10}$

\section{FUENTES Y TEMAS}

El primer bloque, «Images and Representations of Classrooms», empieza con un capítulo de Sjaak Braster bajo el título «Educational Change and Dutch Classroom Photographs». Braster nos sumerge en un análisis comparativo de imágenes de principios de siglo xx e imágenes de finales del mismo siglo a partir de dos análisis: cualitativo y cuantitativo. Esta peculiaridad de introducir el análisis cuantitativo para el estudio de imágenes no está exenta de limitaciones, como el mismo autor apunta, aunque al mismo tiempo nos abre la puerta a otra metodología de trabajo con imágenes.

En el siguiente capítulo, Ian Grosvenor nos expone el camino histórico que mapas, copias de pinturas y litografías, entre otros objetos, han seguido desde finales del siglo XVIII hasta después de la Segunda Guerra Mundial, y su estrecha vinculación con la escolarización de masas, la construcción de escuelas modernas y el incremento de la cultura visual en todos los ámbitos de la vida social. Estos artefactos fueron fuente de controversia entre la comunidad, y esto no hace más que significar que la aleatoriedad de los mismos no existía, sino que su disposición era a voluntad de maestros, autoridades, asociaciones de filántropos o publicistas, convirtiéndolos, de este modo, en artefactos políticos.

Para finalizar este primer bloque, Jeremy Howard, bajo el título «Classroom Genres. Aspects, Values and Interpretations of Painted

\footnotetext{
${ }^{10}$ Wright, «Inside the Black Box?»,126. «Para dar sentido a las a menudo eufemísticas e indirectas notas de los libros de texto, relevantes para mis áreas de estudio, me baso en otras fuentes primarias y secundarias de investigación. Pero incluso con estas pruebas adicionales hay que tener precaución, ya que utilizando esta estrategia uno corre el riesgo de poner palabras en boca del profesor, leyendo en sus notas algo que dijo con otra intención».
} 
School Interior Scenes», nos ofrece a través de cuatro obras pictóricas espaciadas en el tiempo y el espacio una nueva fuente para el análisis de la Caja Negra. El análisis de las obras nos conduce inevitablemente, por la particularidad de la fuente misma, a una interpretación de la visión subjetiva de los pintores.

En el segundo bloque «Writings and Documents Inside Classrooms» encontramos la utilización de fuentes documentales que tienen como eje central el individuo. El primer capítulo, de Ana Badanelli y Kira Mahamud, nos adentra en el aula de la posguerra española a través de cuadernos escolares de niñas y niños. Algunas de las conclusiones a las que llegan son insólitas, aunque esto no implique que la ideología nacionalcatólica del franquismo no fuera el puntal de cada lección o ejercicio. Por ejemplo, el estudio reveló que materias como Hogar y Formación Política tenían relativamente poco peso en los cuadernos de las niñas, aunque fueran materias propias. También sorprendió el trabajo que cada mes de mayo los niños dedicaban a la Virgen María. En resumen, los resultados alrededor del género fueron inesperados, porque no se encontraron disimilitudes notables en la elaboración de ejercicios de niños y ejercicios de niñas, ni tampoco que los maestros establecieran diferencia alguna; desmontando la hipótesis inicial que apuntaba que en los ejercicios de las niñas se encontrarían más valores alrededor de la belleza, la higiene o la pulcritud.

A este segundo bloque le sigue el estudio de las profesoras Del Pozo Andrés y Rabazas acerca de una interesante investigación que bien podría ser, tal y como afirman, los primeros estudios de etnografía escolar en España. Del Pozo y Rabazas exploran las posibilidades de los trabajos en prácticas de estudiantes de Pedagogía, desde la perspectiva del observador, que triangula con otros dos roles - actor y reportero-, como categoría historiográfica. Estos trabajos tienen la valía de ofrecernos una percepción desde el experto —en este caso, el estudiante de Pedagogíamás independiente que la que nos podrían ofrecer otras memorias de profesores o inspectores.

Para cerrar este segundo bloque, la profesora de la Universidad de Oxford-Brookes, Susannah Wright, centra su investigación en el recorrido desde finales del siglo XIX hasta la segunda mitad del XX alrededor de distintas escuelas elementales inglesas. Su fuente principal son los 
libros de registro de la escuela. Wright apunta que estos diarios, aunque limitados, son muy valiosos, no solo por lo que dicen - recogen el día a día escolar y algunos aspectos de la vida de la comunidad en la cual está asentada la escuela-, sino también por lo que no dicen.

La primera aportación al tercer bloque corre a cargo de Antonio Viñao. El bloque entero está dedicado a los egodocumentos como fuente para el análisis de la historia del aula. En concreto, para Viñao las biografías, las memorias y diarios de maestros y maestras son una fuente valiosa para la historia de la educación. Dentro de sus oportunidades como fuente, estos documentos nos ofrecen no solamente información sobre el individuo, sino también sobre el mundo que lo rodea, así como sobre el espacio y el tiempo en el que se insertan, de modo que representan un amplio abanico de posibilidades. Aunque también cabe destacar en algunos casos la desconfianza que generan por su posible efecto de nostalgia o amargura al ser escritos más tarde de cuando las experiencias fueron vividas.

Arianne Baggerman, en su inspirador título «Pandora's Box. Classrooms and Equipement in the Memory of Autobiographers», nos sumerge, al igual que Viñao, en las autobiografías, pero en este caso de maestros holandeses a partir del siglo XVI. Para Baggerman estos documentos son la más peligrosa de todas las fuentes, por lo que requieren de un análisis cuidadoso, no solo de los contenidos que explicitan, sino también de sus silencios. Su capítulo gira alrededor de tres acontecimientos, pero destaca especialmente uno: la desaparición de la férula y la entrada de la regla, así como la utilización de nuevo material no diseñado específicamente para el castigo, pero utilizado con el mismo fin.

Para completar este tercer capítulo, Theo Veld recurre a un viaje personal autobiográfico en el que se pregunta acerca de lo que puede aportar la historia oral en la historia de la educación, y, en concreto, en la del desarrollo de la escuela moderna en los Países Bajos.

Alexander Koutamanis y Yolanda Majewski-Steijns son los encargados de abrir el penúltimo bloque «Space and Design of Classroom». Bajo el título "An architectural View of the Classroom», las autoras describen la evolución de la historia de la educación desde una perspectiva arquitectónica, y cómo la introducción de nuevos elementos en el aula, por 
ejemplo el ordenador, tendría que llevar a una nueva distribución del espacio. No debemos olvidar el papel fundamental de la arquitectura en el descubrimiento de la Caja Negra, básicamente porque esta se limita, se impone y se compone a través de ella.

$\mathrm{Al}$ estudio de Koutamanis y Yolanda Majewsi-Steijns le sigue la investigación de Catherine Burke. Su punto de mira son los murales escolares como una extensión arquitectónica en la escuela de la primera mitad del siglo xx. Burke, al igual que Grosvenor, nos adentra en un recorrido histórico de la cultura visual en educación. Además, tal y como apunta la autora, para los historiadores de la educación explorar la cultura visual y material de la escuela puede llevarnos al desarrollo de nuevas metodologías.

Como cierre a este penúltimo bloque, el libro recoge el capítulo de Frederik Herman, Angelo Van Gorp, Frank Simon y Marc Depaepe. Bajo el título «The Organic Growth of the Decroly School in Brussels. From Villa to School, from Living Room to Classroom», los autores recorren la trayectoria espacial y social de la historia de la escuela decrolyana, con sus transformaciones, adaptaciones y su perdida de identidad doméstica para emprender otra identidad más arquetipada.

El último bloque está comprendido por un capítulo de Jacques Dane, Sarah-Jane Earle y Tijs van Ruite sobre objetos materiales en la clase. Los autores se zambullen en la historia de la clase a través de la evolución del work-wall como espacio central educativo en el que todos los objetos se disponían, de los pósteres utilizados intencionadamente para transferir conciencia nacional y responsabilidad pública, y de los distintos pupitres utilizados.

\section{ALGUNAS REFLEXIONES A MODO DE CONCLUSIÓN}

Desentrañar la Caja Negra es el objetivo que se han propuesto los editores del libro. Su lectura, más allá de descubrir algunos de los procesos que ocurrieron dentro de ella, me ha planteado nuevos interrogantes.

La Caja Negra tiene ya su estatus dentro de la historia de la educación, pero hasta dónde debemos llegar con su estudio todavía no tiene respuesta. Como tampoco tiene respuesta con qué fuentes contamos en 
un futuro para su estudio. Jeremy Howard, en este sentido, nos abre la puerta a plantearnos la utilización de fuentes que hoy en día parecen inimaginables, o como mínimo de entrada sorprendentes. Su capítulo referente a las tipologías de aulas representadas por distintos pintores no solo nos conduce al estudio de la Caja Negra desde fuentes lejanas al aula, en el sentido que no han sido producidas ni para la escuela ni en la escuela, ${ }^{11}$ sino que se atreve a apostar en su última pincelada final, con fuentes que pueden generar a priori algunos recelos pero que abren seguramente nuevas miradas en historia de la educación que restan cerradas al día de hoy:

It is not, however, just painters who have visualised the makeup of schooling, but sculptures, printmakers, and mixed-media, installation, performance and theatre artists. And ultimately, there may well be lessons to be learned about the history of the school from such diverse sources as teachers' gravestones and pop album covers. ${ }^{12}$

En el fondo, Howard se está preguntando algunos interrogantes que también se plantean otros autores a lo largo del libro. ¿A dónde debemos o podemos acudir para desentrañar la Caja Negra? ¿Debemos ir a fuera para comprender los fenómenos que pasan dentro de una forma que nos aproxime a una visión lo máximo holística posible? Completarse con aquello que se encuentra fuera implica necesariamente el apoyo de otras disciplinas principalmente por dos aspectos. En primer lugar, el investigador especializado en una materia necesita de la formación en otros ámbitos que le posibiliten comprender algunos de los fenómenos que están fuera de su campo de formación. En segundo lugar, implica también la constitución de equipos interdisciplinarios.

En este recorrido del dentro y el fuera no quiero olvidarme del significado del aula. Si hablamos de dónde podemos acudir para desentrañar

\footnotetext{
${ }^{11}$ Aunque es evidente que los cuadros de los artistas que analiza Howard son producidos en la escuela, no constituyen un producto escolar.

${ }^{12}$ Jeremy Howard, «Classroom Genres. Aspects, Values and Interpretations of Painted School Interior Scenes», en The Black Box of Schooling, 77. «No son solo los pintores los que han visualizado el aspecto de la escuela, sino que también lo han hecho escultores, grabadores, instaladores y actores de teatro. De hecho, seguramente hay cosas que aprender sobre la historia de la escuela en fuentes tan diversas como las lápidas de los maestros o las portadas de los álbumes de pop».
} 
el dentro es porque entendemos su significación per se. Pero ¿no existe el aula sin paredes? O, como apuntan Herman, Van Gorp, Simon y Depaepe: "In the writing of a history of the classroom, the journey metaphor may well be able to lift us over the physical boundary of the classroom walls, for is not the classroom everywhere?». ${ }^{13} \mathrm{Si}$ el aula, está en todas partes, ¿estará también la Caja Negra en estas? O, si desaparece el aula ¿desaparece la Caja Negra? En cualquier caso, tal y como apuntan Koutamanis y Majewski-Steijns en su capítulo sobre arquitectura escolar, el aula será seguramente una de las constantes invariables hasta el final, y lo que la reemplazará está todavía por determinar. ${ }^{14}$

Rosa Sambola Alcobé Universidad de Vic-Universidad Central de Cataluña rosa.sambola@uvic.cat

\footnotetext{
${ }^{13}$ Frederik Herman, Angelo Van Gorp, Frank Simon, Marc Depaepe, «The Organic Growth of the Decroly School in Brussels. From Villa to School, from Living Room to Classroom», en The Black Box of Schooling, 257.

${ }^{14}$ Alexander Koutamanis \& Yolanda Majewski-Steijns, «An Architectural View of the Classroom», en The Black Box of Schooling, 222. "Escribiendo la historia de una clase, ¿nos puede levantar la metáfora del viaje por encima del límite físico de las paredes del aula, si es que el aula no está en todas partes?».
} 